\title{
Induction of Fertile estrus in true anoestrus by re-utilization of Crestar implants in She buffales
}

\author{
Mahesh S.Dodamani*, M.K.Tandle, Khaja Mohteshamuddin and S.S.Honnappagol \\ Department of Animal Reproduction, Gynaecology and Obstetrics, \\ ${ }^{1}$ Department of Veterinary Pharmacology and Toxicology \\ Veterinary College, Karnataka Veterinary and Fishery Science University, \\ Nandinagar, P.B.No-6, Bidar-585401, India. \\ * Corresponding author email: maheshdodamani@gmail.com
}

\begin{abstract}
The effect and economy of re-utilization of Crestar implant alone and in combination with PMSG for induction of fertile estrus in 30 true anoestrus she buffaloes was conducted in and around Bidar district of Karnataka state. The animals were randomly divided into three groups of ten animals each. The animals in Group 1 and 2 were injected with $500 \mathrm{mg}$ progesterone intramuscularly followed by implantation of used Crestar on day 4 of progesterone administration and removed on day 9, whereas animals in Group 2 were injected with 500 IU PMSG on day 9 (the day of implant removal). whereas Group 3 served as control group. On removal of the implant, $70.00 \%$ she buffaloes from Group 1 and 2 exhibited estrus $(2.60 \pm 0.80$ and $2.47 \pm 0.73$ days $)$ respectively. The animals were artificially inseminated twice with $12 \mathrm{hrs}$ interval and conception rate was $70 \%$ from animals of Group 1 and 2 . No extra beneficial effect of PMSG was observed either on estrus response or conception rate. None of the animals from Group 3 (control) showed estrus. The animals of Group 1 and 2 exhibited 25 and $45 \%$ and 50 and 20\% intense and intermediate estrus respectively with absolute conception, while $30 \%$ of the animals in both the treated groups exhibited weak symptoms of estrus and failed to conceive. $70 \%$ of the animals from both the groups had satisfactory arborization patterns with 66.67 percent conception. Whereas only 20 percent of the animals in both the groups showed good arborization patterns of cervico- vaginal mucus with absolute conception. None of the animals conceived expressing weak symptoms of estrus and missing arborization pattern in both the treated groups. It was concluded that utilized Crestar implant (for 7 days) can also be re-utilized to reduce the cost of treatment for induction of fertile estrus even with out PMSG in field conditions.
\end{abstract}

Keywords: Crestar re-utilization, estrus induction, arborization, fertility, she buffalo

\section{I ntroduction}

Anoestrus due to ovarian inactivity and ovarian irregularities are the most important, frustrating and challenging problems associated with buffalo reproduction. Higher incidences of anestrous are due to inactive ovaries in she buffaloes than in cows have been reported by Tanwar et al. (2003). In non-cycling true anoestrus animals, the primary effect of Norgestomet is enhanced by combining the effect of the implant removal and an injection of small dose of PMSG to stimulate follicular development.. Crestar is a white silicon polymer containing $3 \mathrm{mg}$ norgestomet and $5 \mathrm{mg}$ estradiol valerate. Kundu (1998) utilized 1 1/2 and 2 implants of Crestar for induction of estrus. reutilization of Crestar implants for estrus induction in she buffaloes was conducted under field condition at farmer's door step. Keeping this in view, an effort was made with PMSG and progesterone in field condition. Re-utilisation of crestar implants for induction of esters in she buffaloes enhanced conception rate

\section{Material and Methods}

The experimental study was conducted on 30 anestrous she buffaloes, aged 8-10 years, maintained under field conditions. True anoestrus was diagnosed in the animals on the basis of anamnesis and conducting gynaeco-clinical examinations twice, at 10 days interval, finding smooth inactive ovaries, flaccid uterine horns, and non-relaxed (closed) cervix. The animals were randomly divided into three groups of ten animals each and were subjected to the treatment regimens given in Table 1 . Prior to the initiation of therapy, all the animals were dewormed with a broad spectrum anthelminthic (albendazole@ $10 \mathrm{mg} / \mathrm{kg} \mathrm{BW}$, oral).

The estrus was detected by behavioral symptoms and rectal examination of genitalia. Buffaloes exhibiting estrus were allowed for double artificial insemination with $12 \mathrm{hrs}$ interval. The estrus intensity was recorded as intense (standing), intermediate and weak. The arborization pattern was 
Table-1: Experimental plan and Treatment protocol.

\begin{tabular}{lclll}
\hline Group & No of animals & Day $\mathbf{0}$ & 4th Day & 9th Day \\
\hline 1 & 10 & Progesterone 500mg I/M & Utilized Crestar implanted & Implant removed \\
2 & 10 & Progesterone 500mg I/M & Utilized Crestar implanted & Implant removed and PMSG 500 IU I/M \\
3 & 10 & Controls(No Treatment) & No Treatment & No Treatment \\
\hline
\end{tabular}

analyzed under low power (10x) microscope and classified as good, satisfactory and unsatisfactory/ missing (Hafez, 2000). All the buffaloes of the treatment groups were examined gynaeco-clinically on the $12^{\text {th }}$ day post service for presence of the corpus luteum. Whereas, Pregnancy was confirmed perrectally 60 days after breeding. The fertility response of different treatment regimen was evaluated in relation to intensity of estrus and arborization pattern. The statistical analysis was carried as per Snedecor and Cochran, 1994.

\section{Results and Discussion}

The re-utilisation of Crestar implant alone and in combination with $\mathrm{PMSG}$ is significant $(\mathrm{P}<0.05)$ in group II as compared to group I in estrus induction $(2.47 \pm 0.73$ days $)$, which was in agreement with Macmillan et al, 1989. Whereas there was significant $(\mathrm{P}<0.05)$ difference in arborisation pattern and conception \% in group II compared to group I. However, Rao (1984) observed better estrus response (96.67 percent) by injecting $25 \mathrm{mg}$ progesterone daily for 7days followed by 1000 IU of PMSG on the last day of progesterone treatment in buffaloes. Whereas, Kumar et al. (2000) induced pronounced estrus only in $25 \%$ of crossbred cows within 2.50 .5 days with 100 $\%$ conception by injecting $50 \mathrm{mg}$ of progesterone daily for 5 days followed by an intramuscular injection of Estradiol valerate $5 \mathrm{mg}$ on the $7^{\text {th }}$ day of treatment.

The poor response for intense and intermediate

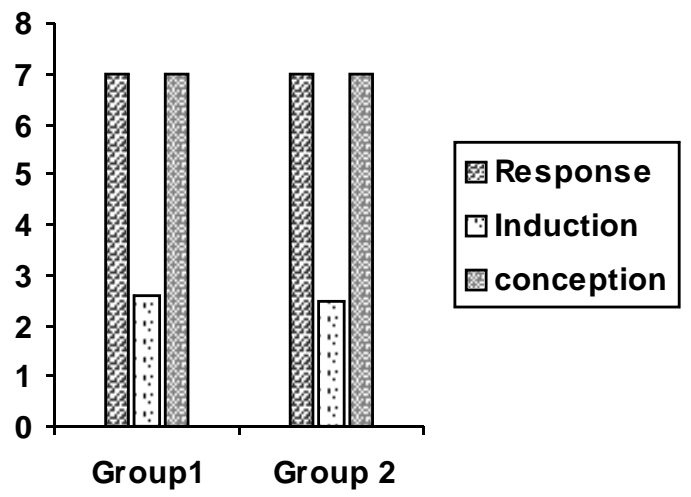

Graph 1: Post treatment response of anoestrous in She buffaloes estrus in both the treated groups be due to prolonged half life of Progesterone which lowers the estrogen levels required for the manifestation of estrus (Hafez, 1993), whereas there was no difference in both the treated groups in arborisation pattern and conception percentage $(70 \%, 66.67 \%)$. As observed in the present study, various other workers also observed that the conception rate was highest with good to satisfactory arborization pattern and nil when it was missing (Kumar, 1989; Chhatry, 1998 and Nzar, 2004).

Our findings are supported by the reports of

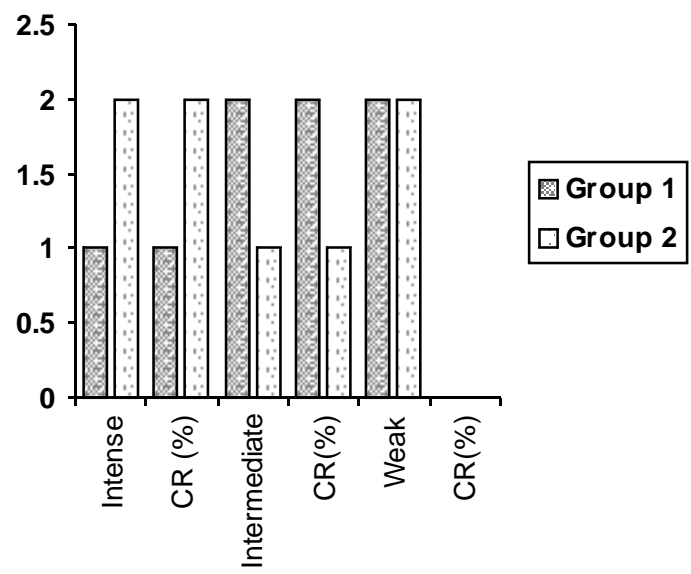

Graph 2: Post treatment response of estrous intensity in relation to fertility $(n=10)$

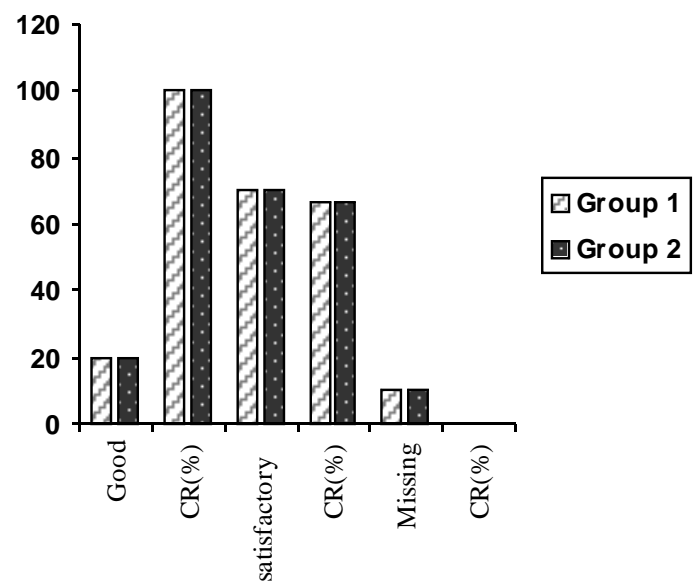

Graph 3: Group wise conception rate according to the quality of arborization pattern of ervico-vaginal mucus 
Sahasrabudhe (1995), who also reported 92.31 and 75 $\%$ conception rate with good and satisfactory arborization patterns, respectively. Similarly, Rathore (2004) also reported 80 and $71.43 \%$ conception with the best and average arborization pattern in buffaloes

Re-utilisation of Crestar implants for induction of fertile estrus even without PMSG in true anestrous she buffaloes was beneficial when compared to administration of other hormonal supplements like Progesterone \& PMSG.

\section{References}

1. Chhatry, U. (1998). Efficacy of synchronization of estrus in true anoestrus buffalo during breeding and low breeding season using norgestomet implant. M.V. Sc. Thesis, JNKVV, Jabalpur.

2. Hafez, E.S.E. (1993). Reproduction in Farm Animals, 6th ed. Lea and Febiger, Philadelphia.

3. Hafez, E.S.E. (2000). Reproduction in Farm Animals, 7th ed. Publ., Lippincott Williams and Wilking Co., Philadelphia.

4. Kumar, N., S. et.al. (2000). Induction of estrus and ovulation in post -partum anesturs crossbred cows with short term treatment. Indian J. Anim. Reprod., 21:53-54.
5. Kumar, S. (1989). Conception rate in relation to estrus cervical mucus crystallization fern pattern in buffaloes. LivestockAdvisor., 14(12): 25-27.

6. Kundu, A.S. (1998). Management of summer anestrus in postpartum buffaloes with norgestomet-estradioleCG combination clincial and endocrine studies. M.V. Sc. Thesis, CCS Hariyana Agri. Uni. Hissar.

7. Macmillan, K.L., A.M. Day and V.K. Toufa. (1989) Problem of non cycling cows. Proc. Prakura Farmers. Conf., 41: 15-18.

8. Nzar. (2004). Studies on induction of estrus in suboestrus crossbred cows using sodium di-hydrogen phosphate and PGF2 alpha. M.V. Sc. Thesis, JNKVV, Jabalpur.

9. Rao, S.K. (1984). A study on treatment of anoestrus in buffaloes with certain hormones. M.V.Sc. Thesis, A n d h r a Pradesh Agriculture University, Tirupati.

10. Rathore, K.K. (2004). Studies on treatment of anoestrus in Murrah Buffaloes. M.V. Sc. Thesis, JNKVV, Jabalpur.

11. Sahasrabudhe, S.A. (1995). Fertility respone in suboestrus buffaloes treated with prostaglandin F2 alpha through different routes during summer. M.V.Sc. Thesis, JNKVV, Jabalpur.

12. Snedecor,G.W. and Cochran,W.G.(1994). Statiscal Methods eighth edition, Iowa.

13. Tanwar, P.S., N.K. Rakha and J.B. Phogat. (2003). Challenges in buffalo infertility. Intas Polivet., 4(11): 121-127. 